\title{
Stated Preferences of Alaska Resident Saltwater Anglers for Contemporary Regulatory Policies
}

\author{
DANIEL K. LEW and DOUGLAS M. LARSON
}

\section{Introduction}

Saltwater recreational fishing in Alaska occurs almost exclusively in two regions: Southeast Alaska and Southcentral Alaska (Fig. 1). The primary saltwater fish targeted by recreational anglers in these regions are Pacific salmon, Oncorhynchus spp.; especially Chinook salmon, $O$. tshawytscha, and coho salmon, $O$. kisutch; and the Pacific halibut, Hippoglossus stenolepis. Fishery managers rely on bag and size limit restrictions as the principal management tools to manage harvest levels for these species. For state-managed salmon, bag limits and minimum size limits (mini-

Daniel K. Lew is an economist in the Resource Ecology and Fisheries Management Division, Alaska Fisheries Science Center, National Marine Fisheries Service, NOAA, 7600 Sand Point Way NE, Seattle WA, 98115; and visiting scholar in the Department of Environmental Science and Policy, University of California, One Shields Avenue, Davis, CA 95616. Douglas M. Larson is a Professor in the Department of Agricultural and Resource Economics and member of the Giannini Foundation of Agricultural Economics at the University of California, One Shields Avenue, Davis, CA 95616. The corresponding author is Dan Lew (e-mail: Dan.Lew@noaa.gov).

doi: https://doi.org/10.7755/MFR.79.3-4.2 mum length of a fish) vary depending upon the time of year and specific location. ${ }^{1}$ For federally managed Pacific halibut, bag limits (two fish per day of any size for both unguided and guided/ charter boat anglers) ${ }^{2}$ were the primary management tool used until 2007.

Since then, management of the Pacific halibut sport fishery in Alaska has undergone a number of significant changes due to concerns over declining stock abundance and distribution, size at age, and allocation disputes between commercial and recreational charter boat fishing interests. Of principal concern are the changes directly affecting anglers ${ }^{3}$ - the traditional bag limit regulatory structure for this fishery has been retained, but with a variety of new features such as different size limits for different fish in the bag limit, and "large-or-small fish" size limits that have both a maximum size limit and a higher minimum size limit.

\footnotetext{
${ }^{1} \mathrm{~A}$ detailed discussion of the recent history of Pacific halibut fishery regulation can be found in Lew and Larson (2015) (current regulations can be found at http://www.adfg.alaska.gov/index.cf $\mathrm{m}$ ?adfg=fishingSportFishingInfo.main).

${ }^{2}$ As used here, guided fishing refers to fishing on for-hire trips.

${ }^{3}$ For a full description of recent changes, see
} NOAA (2013).
These so-called "reverse slot" regulations are designed to protect fish in the intermediate size (and age) range, since they are especially important for reproduction.

To help understand the trade-offs between regulatory tools for managing charter halibut harvest, it is important to understand how angler values are affected. The most common approach used in recent years to evaluate the effect of harvest restrictions on recreational fishing values is the stated preference (SP) method (i.e., Criddle et al., 2003; Carter and Liese, 2012; Anderson and Lee, 2013; Lew and Larson, 2012, 2014, 2015). Stated preference methods use responses to carefully-constructed questions typically asked in a survey to provide information about people's preferences and values (Mitchell and Carson, 1989; Bateman et al., 2002; Kanninen, 2006). The principal reason for the popularity of these methods in fisheries applications is that fishery managers are often interested in the effects of angler harvest regulations under consideration that have yet to be tried, which precludes collection of data on how people respond to the regulations.

One particular type of SP method,
ABSTRACT-Over the last several years, there have been substantial changes to the harvest regulations governing the $\mathrm{Pa}$ cific halibut, Hippoglossus stenolepis, fishery off Alaska, notably in the recreational charter boat fishing sector. One change has involved anglers fishing from charter (for hire) boats being subject to increasingly restrictive harvest regulations that do not apply to other anglers. This article analyzes how the economic values that Alaska resident anglers place on charter and private boat fishing is affected by these regulations, which consist of bag and size limits. This information can be helpful to fishery managers in assessing the tradeoffs in economic benefits associated with different regulatory tools used to manage angler harvest levels. Using stated preference data from a 2012 survey, we estimate panel rank-ordered mixed logit models to estimate the economic value, or willingness to pay (WTP), Alaska resident anglers place on boat-based saltwater fishing trips in the two principal regions in which saltwater fishing occurs, Southeast Alaska and
Southcentral Alaska. The results indicate that Alaska resident anglers have strong preferences for private boat fishing in both regions, with mean values ranging from $\$ 172$ to over $\$ 2,000$ per trip, depending upon the species targeted, the regulations, and which region the fishing occurred. Our analysis also suggests that Alaska resident anglers place much less value on charter boat fishing trips for halibut in Southcentral Alaska that are subject to the kinds of restrictive bag and harvest restrictions seen in recent years. 


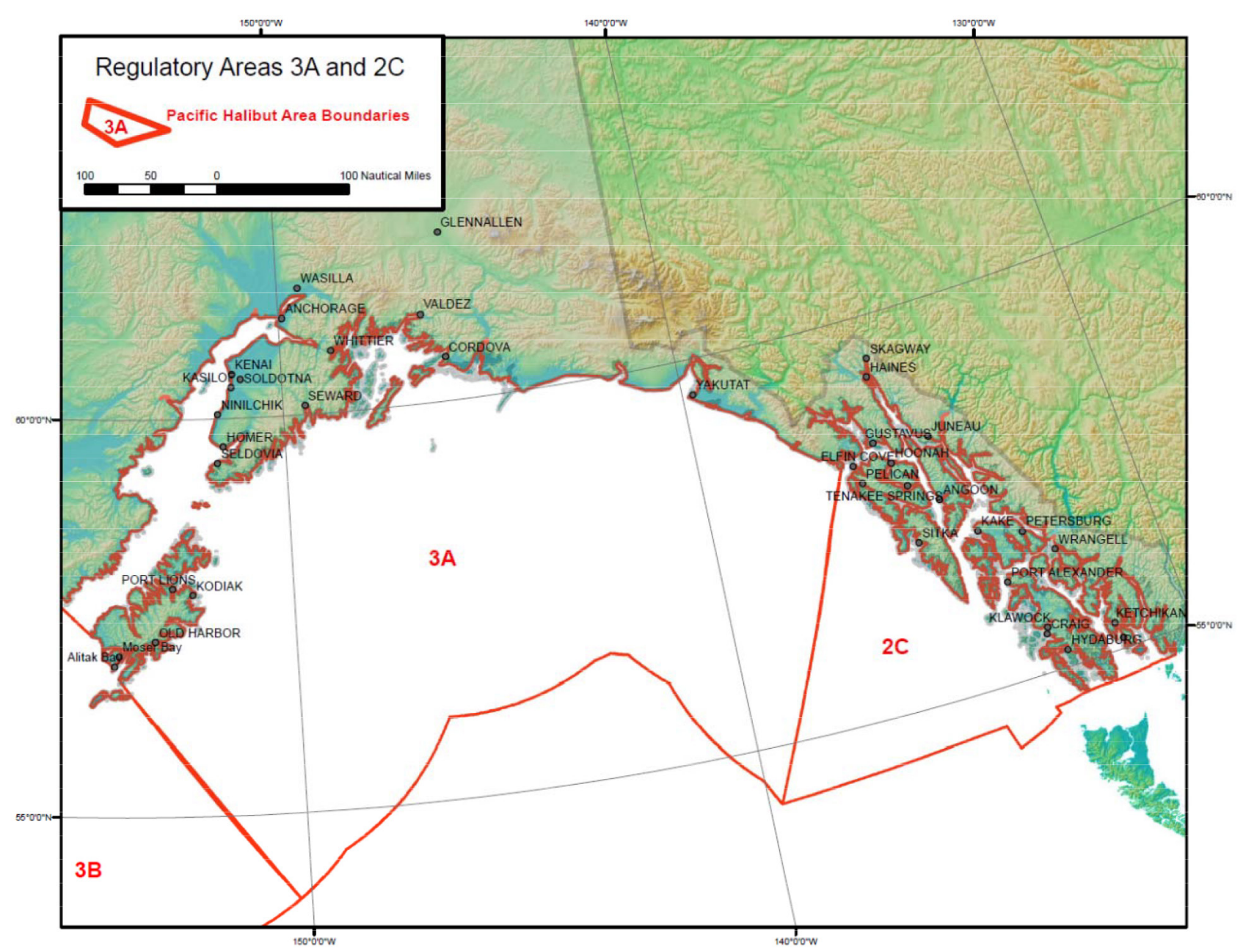

Figure 1.- International Pacific Halibut Commission regulatory areas: Southeast Alaska (2C) and Southcentral Alaska (3A) (source: http://alaskafisheries.noaa.gov/sustainablefisheries/halibut/sport.htm).

the choice experiment (CE), has increasingly been used for valuing the effects of angler harvest regulations because of its ability to provide economic value information across a range of potential policy changes (Kanninen, 2006). Choice experiment questions present a choice between two or more alternatives (e.g., fishing trip options) that are described in terms of several attributes (e.g., trip cost, regulations, fish targeted), one or more of which are policy variables (e.g., bag or size limits). Surveys will generally contain multiple CE questions that differ in the levels of the attributes that make up each option, so a great deal of information about a per- son's preferences is obtained parsimoniously. Random utility maximization (RUM) models (Louviere et al., 2000) are used with CE responses to predict the probability that a given respondent will choose a particular alternative, and from this both the marginal value of individual attributes and the value of a policy containing several attributes are obtained.

This article investigates how the economic values received by Alaska resident saltwater recreational anglers are affected by different configurations of bag and size limits that are either contemplated for the future or are now in use. The focus on Alaska resident anglers distinguishes this work from Lew and Larson (2015), which focused on nonresident anglers (i.e., anglers who lived outside Alaska). In this study, we use CE data from a 2012 survey of Alaska resident anglers and the methodology of Lew and Larson (2015), who analyzed economic values for halibut and salmon fishing trips associated with Alaska nonresidents, to provide comparable estimates of the values received by residents of both Southcentral and Southeast Alaska. In addition to providing estimates of status quo values, we analyze how these values change with different regulatory configurations. Because they are described well elsewhere in the literature (Lew and Larson, 2015), our dis- 


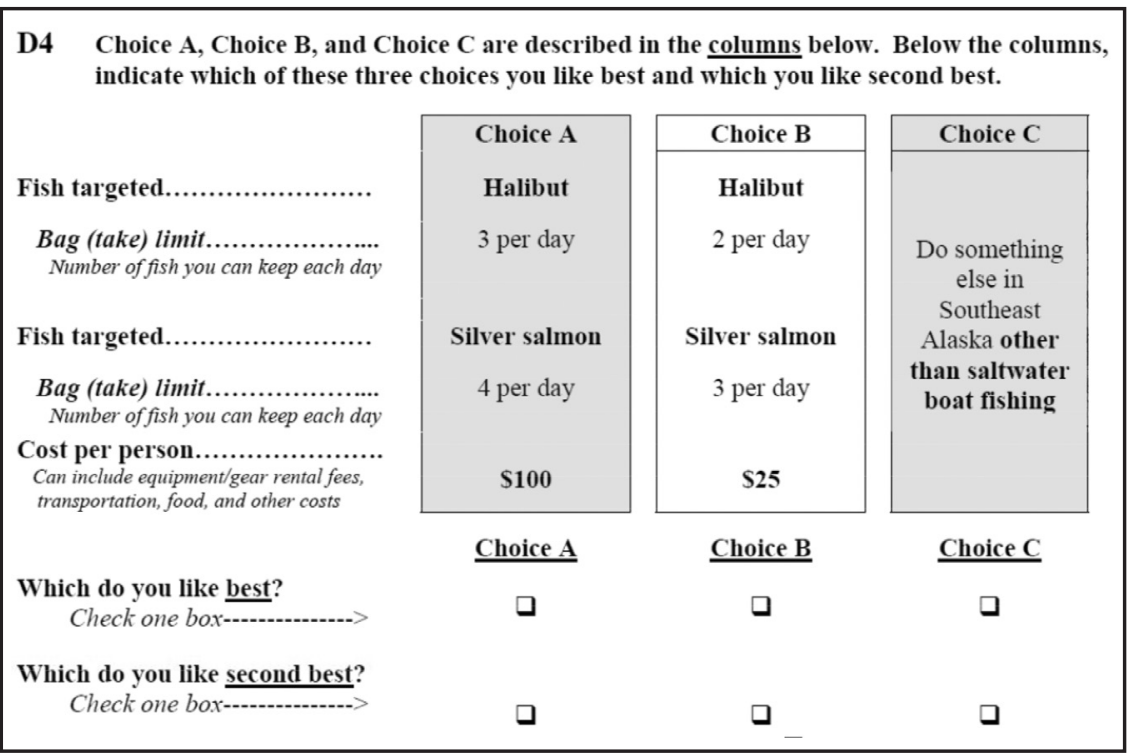

Figure 2.-Example of SE version choice experiment question. Note: The survey uses the common names for Chinook and coho salmon used by anglers in Alaska, king and silver salmon, respectively.

\begin{tabular}{|c|c|c|c|}
\hline \multirow[b]{2}{*}{ 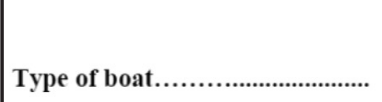 } & Choice A & Choice B & Choice C \\
\hline & Charter boat & Private boat & \multirow{8}{*}{$\begin{array}{c}\text { Do something } \\
\text { else in } \\
\text { Southcentral } \\
\text { Alaska other } \\
\text { than saltwater } \\
\text { boat fishing }\end{array}$} \\
\hline Number of fishing days............ & 2 days & 2 days & \\
\hline 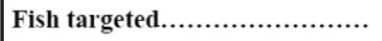 & Halibut & Halibut & \\
\hline $\begin{array}{l}\text { Bag (take) limit...................... } \\
\text { Number of fish you can keep each } \\
\text { day (and in total) }\end{array}$ & $\begin{array}{l}3 \text { per day } \\
\text { (6 total) }\end{array}$ & $\begin{array}{l}3 \text { per day } \\
\text { (6 total) }\end{array}$ & \\
\hline $\begin{array}{l}\text { Size restriction...................... } \\
\text { Restricts the size of fish in the per day } \\
\text { bag limit (length limits converted to } \\
\text { pounds) }\end{array}$ & $\begin{array}{l}1 \text { fish any size; } 2 \\
\text { fish no larger } \\
\text { than } 18 \mathrm{lbs}\end{array}$ & $\begin{array}{l}\text { No size } \\
\text { restriction }\end{array}$ & \\
\hline Fish targeted............................. & Silver salmon & Silver salmon & \\
\hline $\begin{array}{l}\text { Bag (take) limit........................... } \\
\text { Number of fish you can keep each } \\
\text { day (and in total) }\end{array}$ & $\begin{array}{l}6 \text { per day } \\
\text { (12 total) }\end{array}$ & $\begin{array}{l}6 \text { per day } \\
\text { (12 total) }\end{array}$ & \\
\hline \multirow[t]{2}{*}{$\begin{array}{l}\text { Cost per person.............................. } \\
\text { Can include charter/rental fees, } \\
\text { transportation, food, and other costs }\end{array}$} & $\$ 1,400$ & $\$ 1,000$ & \\
\hline & Choice A & Choice B & Choice C \\
\hline $\begin{array}{l}\text { Which do you like best? } \\
\text { Check one box----- }\end{array}$ & ב & ב & घ \\
\hline $\begin{array}{l}\text { Which do you like second best? } \\
\text { Check one box-m-a }\end{array}$ & a & ב & ב \\
\hline
\end{tabular}

Figure 3.-Example of SC version choice experiment question. Note: The survey uses the common names for Chinook and coho salmon used by anglers in Alaska, king and silver salmon, respectively. cussions of the data and methods used are somewhat succinct.

\section{Data}

Data for this analysis are from a mail survey conducted during the first half of 2012 of Alaska resident anglers who purchased Alaska sport fishing licenses during 2011. ${ }^{4}$ The survey was very similar in content to a 2007 survey of Alaska resident anglers (Lew et al., 2010) but was reworked to acknowledge changes in harvest regulations that have occurred in recent years (primarily size restrictions on Pacific halibut for charter boat anglers). It was pretested with Alaska saltwater fishermen via cognitive interviews (Willis, 2005) held in two Alaska cities (Juneau and Anchorage). Fisheries analysts involved in Alaska fishery management also provided valuable input that was incorporated into the survey design.

Surveys contained four CE questions, each of which offered two saltwater boat fishing trips and a third nonsaltwater boat fishing option. Respondents were asked to choose the options they liked best and second best, which allows for a full rank ordering and provides more information than simply modeling which option is preferred. Two separate versions of the survey were developed-the first for resident anglers who live in Southeast Alaska, referred to as the SE version (Fig. 2), and the second for all other resident anglers, referred to as the $\mathrm{SC}$ version (Fig. 3). The saltwater boat fishing trips in the $\mathrm{CE}$ questions in the $\mathrm{SE}$ version were described as occurring in Southeast Alaska. Due to the size of the state, travel for residents between Southeast and Southcentral Alaska is costly, both in terms of time and money. For this reason, few resident anglers of one region have been observed to fish in the other region in previous survey work (Lew et al.,

${ }^{4}$ Sport fishing licenses are required for both nonresidents and Alaska residents aged 16 or older. Residents 60 years or older do not need a sport fishing license to fish in Alaska, but do need to have a "Permanent Identification Card" (PIC). We include PIC holders in the sampling frame used to select the random samples for this study. 
Table 1.-Choice experiment attributes and levels.

\begin{tabular}{|c|c|c|c|}
\hline \multicolumn{2}{|l|}{ Attribute } & \multicolumn{2}{|c|}{ Levels } \\
\hline \multicolumn{2}{|c|}{$\begin{array}{l}\text { Type of fishing trip (SC version only) }{ }^{1} \\
\text { Length of fishing trip (SC version only) } \\
\text { Chinook salmon daily bag limit } \\
\text { Coho salmon daily bag limit } \\
\text { Halibut bag daily limit } \\
\text { Maximum size limit on 1st fish in limit } \\
\text { Maximum size limit on additional fish in limit beyond 1st fish } \\
\text { Minimum size limit (reverse slot) } \\
\text { Daily total fishing trip cost }\end{array}$} & $\begin{array}{l}\text { Private boat or } \\
1,2 \text {, or } 3 \text { days } \\
1,2 \text {, or } 3 \text { fish } \\
3,4 \text {, or } 6 \text { fish } \\
1,2 \text {, or } 3 \text { fish } \\
\text { No limit, } 18 \mathrm{lb} \text {, } \\
\text { No limit, } 18 \mathrm{lb} \text {, } \\
\text { No min size limi } \\
\$ 25 \text { to } \$ 500\end{array}$ & $\begin{array}{l}28 \mathrm{lb}, \text { or } 35 \mathrm{lb} \\
28 \mathrm{lb} \text {, or } 35 \mathrm{lb} \\
0 \mathrm{lb}^{2}\end{array}$ \\
\hline \multicolumn{4}{|c|}{$\begin{array}{l}{ }^{1} \text { There were two versions of the survey: A version developed for Southeast Alaska resident anglers (SE version) and } \\
\text { version for all other Alaska resident anglers (SC version). There were two attributes in the choice experiment questions } \\
\text { the SC version that did not appear in the SE version. } \\
{ }^{2} \text { Note that this minimize size limit differs from the realized size limits, which are greater. }\end{array}$} \\
\hline Variable & Description & $\begin{array}{l}\text { SE version (Southeast } \\
\text { Alaska resident anglers) }\end{array}$ & $\begin{array}{l}\text { SC version (Other } \\
\text { Alaska residents) }\end{array}$ \\
\hline Gender & $\%$ male & $65.40 \%$ & $61.40 \%$ \\
\hline Age & mean in years & 47.21 & 46.09 \\
\hline Fishing experience & mean years & 31.46 & 29.64 \\
\hline Household size & mean number & 2.31 & 2.53 \\
\hline Ethnicity & $\%$ Caucasian & $88.06 \%$ & $88.14 \%$ \\
\hline Education & $\%$ with college degree or higher & $51.0 \%$ & $55.12 \%$ \\
\hline Household income & mean income & $\$ 84,191$ & $\$ 95,858$ \\
\hline No. in sample & & 335 & 430 \\
\hline
\end{tabular}

2010). Consequently, the CE questions ask about fishing within the resident angler's "home region."

For this same reason, the SC version presented saltwater fishing trip options that would occur in Southcentral Alaska. Attributes in the CE questions in both the SE and SC versions included the species caught - either one or two of the three species available, Pacific halibut, Chinook salmon, and coho salmon; the daily bag (take) limit; size restriction (if any); and the fishing-related costs.

Since saltwater fishing trips in Southeast Alaska typically are day trips only ${ }^{5}$, the number of fishing days on the trip was only included as an attribute in the $\mathrm{SC}$ version of the survey. Moreover, the SC version includes an attribute that indicates whether the fishing trip was on a private or charter boat. Previous survey results suggested that very few Southeast Alaska resi-

\footnotetext{
${ }^{5}$ Based on earlier survey results, about $89 \%$ of Southeast Alaska resident angler saltwater fishing trips were single day trips (Lew et al., 2010). Also, we note that although halibut and Chinook and coho salmon are the primary target species on most Alaska saltwater fishing trips, and thus those modeled in the angler's utility specification, other secondary species like other salmon, rockfish, and lingcod may also contribute towards a fishing trip's value.
}

dents take charter fishing trips (due in part to residents in this region generally having more access to private fishing boats), so the same attribute was not included in the SE version.

There were 30 versions of the SC survey and 20 versions of the SE survey. These versions differed only in the levels of attributes describing the trips; attribute levels are given in Table 1. The combination of attribute levels seen in each of these survey versions was determined using a procedure that the overall experimental design (Huber and Zwerina, 1996).

The survey implementation followed a modified Dillman Tailored Design Method (Dillman et al., 2014), with an advance letter, survey mailing (which included the survey booklet, cover letter, map, business reply envelope, and a small monetary incentive), thank you/reminder postcard, a second full survey mailing, and a follow-up telephone contact. The overall survey response rates for the SE and SC versions were $46.1 \%$ and $41.1 \%$, respectively. ${ }^{6}$ Choice experiment data

${ }^{6} \mathrm{~A}$ total of 1,000 Southeast Alaska anglers and 1,500 other Alaska anglers were randomly selected and contacted to participate (71 and 97 maximized the statistical efficiency of from the two versions were analyzed separately. After removing respondents who did not answer the CE questions consistently or at all, as well as protest responses, the sample sizes used in the analysis were 335 anglers for the SE version analysis and 430 anglers for the $\mathrm{SC}$ version analysis.

The demographic group represented most heavily in both samples was older and very experienced Caucasian male anglers (Table 2). The SE and SC samples were generally very similar in terms of demographics with the majority (between $60 \%$ and $65 \%$ depending on the sample) being male, Caucasian (about 88\%), and having a college degree or higher education (between $51 \%$ and $55 \%$ depending on the sample). Across both samples, the mean age was about 46 or 47 years and mean years of fishing experience was about 30 or 31 years. $^{7}$ There were slight differences in household income between the SE and SC samples, with the SE sample having a lower mean income (about $\$ 84,000$ ) compared to anglers in the SC sample (about $\$ 96,000$ ).

\section{Modeling Approach}

To analyze the CE data, we used the panel rank-ordered random utility maximization model described in Lew and Larson (2015), which explicitly accounts for both the rank-order nature of the CE data (Beggs et al., 1981; Chapman and Staelin, 1982) and the panel nature of the data. This approach avoids the restrictive Independence of Irrelevant Alternatives (IIA) assumption embodied in fixedparameter RUM models by introducing preference heterogeneity, so that some or many parameters are randomly distributed over the population (Train, 2003). To be more precise, in the RUM model the utility (or satisfac-

surveys, respectively, from these two sample strata were undeliverable). The sample sizes used in the analysis exclude respondents who did not answer any of the SP questions.

${ }^{7}$ In contrast, about $75 \%$ of the nonresident angler sample were male, 95\% were Caucasian, mean age was 52.6 years, mean income was a little over $\$ 110,000$, and mean fishing experience was 35 years. In addition, about two-thirds had at least some college education. 
tion) of alternative $j(j=\mathrm{A}, \mathrm{B}$, or $\mathrm{C})$ for question $i(i=1, \ldots, 4)$ is assumed to be composed of a systematic component, consisting of observable characteristics or attributes, and a random component:

$$
U_{i j}=V_{i j}(\boldsymbol{\beta})+\varepsilon_{i j}
$$

where $V_{i j}(\boldsymbol{\beta})$ is the systematic part of utility and a function of attributes for alternative $j$ in question $i, \boldsymbol{\beta}$ are parameters of the utility function, and $\varepsilon_{i j}$ is an independent and identically distributed Type I extreme value (TEV) error term that represents the part of utility unknown to the researcher. Here it is assumed that the non-cost parameters are randomly distributed over the population; that is, these parameters are assumed to follow a normal distribution. To this end, let $\boldsymbol{\beta}_{\mathbf{n}} \in \boldsymbol{\beta}$ be distributed $\beta_{\mathrm{n}} \sim \mathrm{N}\left(\bar{\beta}_{n}, \Omega_{\beta}\right)$, where $\bar{\beta}_{n}$ is a vector of mean parameters and $\Omega_{\beta}^{n}$ is a variance-covariance matrix. In practice, this means two parameters for each random parameter are estimated, a mean and standard deviation, which describe the distribution. The individual is assumed to choose the alternative that yields the most utility out of the available choices ( $\mathrm{A}, \mathrm{B}$, and $\mathrm{C}$ ) in each question as the "best" choice, and the one with the next largest utility as the "second best" choice. Given the assumption about the distribution of the error term $\varepsilon$. (and assuming it is independent across the four CE questions in each survey), the probabilities of observing an individual's choice of best $(j)$ and second best $(k)$ for a single choice question take the form:

$\operatorname{Pr}[j>k>l]=\operatorname{Pr}[j \mid j, k, l] \cdot \operatorname{Pr}[k \mid k, l]$,

where $j, k$, and $l$ are each one of the elements of the available choices (A, $\mathrm{B}$, and $\mathrm{C}$ ) and are not equal to one another, $\operatorname{Pr}[j \mid j, k, l]=\int \exp \left(\mathrm{V}_{j}\right) /\left[\exp \left(\mathrm{V}_{j}\right)\right.$ $\left.+\exp \left(\mathrm{V}_{k}\right)+\exp \left(\mathrm{V}_{l}\right)\right] d \boldsymbol{\beta}$ and $\operatorname{Pr}[k \mid k, l]$ $=\int \exp \left(\mathrm{V}_{k}\right) /\left[\exp \left(\mathrm{V}_{k}\right)+\exp \left(\mathrm{V}_{l}\right)\right] d \boldsymbol{\beta}$ are probabilities evaluated over the distribution of random parameters. This model is estimated by maximum simulated likelihood, where the log-likelihood function is the product of the probabilities in equation 2 over each of the four choice questions. Separate

Table 3.-Variable names and definitions.

\begin{tabular}{ll}
\hline Name & \multicolumn{1}{c}{ Description } \\
\hline Nonregulatory attributes & \\
ASC & Alternative specific constant (dummy variable): 1 = Choice C (nonfishing alternative selected); \\
O otherwise & Dummy variable for private boat trip (vs. charter trip) \\
PRIV & Days fished (length of trip): 1,3 , or 5 days \\
DAY & Per day cost of fishing trip \\
COST & \\
Uniform regulatory variables & \\
HLIM1 & Halibut bag limit dummy: $1=1$ fish; 0 otherwise \\
HLIM2 & Halibut bag limit dummy: $1=2$ fish; 0 otherwise \\
HLIM3 & Halibut bag limit dummy: $1=3$ fish; 0 otherwise \\
KLIM1 & Chinook salmon daily bag limit dummy: $1=1$ fish; 0 otherwise \\
KLIM2 & Chinook salmon daily bag limit dummy: $1=2$ fish; 0 otherwise \\
KLIM3 & Chinook salmon daily bag limit dummy: $1=3$ fish; 0 otherwise \\
SLIM1 & Coho salmon daily bag limit dummy: $1=3$ fish; 0 otherwise \\
SLIM2 & Coho salmon daily bag limit dummy: $1=4$ fish; 0 otherwise \\
SLIM3 & Coho salmon daily bag limit dummy: $1=6$ fish; 0 otherwise \\
HBL & Pacific halibut daily bag limit (if present): 1,2, or 3 fish; 0 otherwise \\
HMIN & Halibut minimum size limit in place (dummy variable): $1=$ yes; $0=$ no \\
& \\
Differentiated regulatory & variables \\
HMAX1 & Halibut maximum size limit on first fish (dummy variable): $1=$ yes; 0 otherwise \\
HMAX2 & Halibut maximum size limit on additional fish beyond 1 st fish (dummy variable): \\
HALSIZE1 & 1 = yes; 0 otherwise \\
HALSIZE2 & Halibut maximum size limit on first fish (integer): $0,18,23,28$, or 35 \\
HNOMAX1 & Halibut maximum size limit on add'l. fish beyond 1st (integer): $0,18,23,28$, or 35 \\
HNOMAX2 & Dummy variable for whether the first fish in halibut bag limit has no size restriction \\
\hline
\end{tabular}

models were estimated for the CE data from the SE sample (SE model) and SC sample (the SC model).

\section{Model Specification}

The systematic component of utility associated with the fishing trip alternatives (Choices A and B in each question) was assumed to be a linear-in-parameters function of two types of variables: non-regulatory and regulatory.

\section{Nonregulatory Variables}

For both the SE and SC models, the nonregulatory variables include an alternative-specific constant (ASC) associated with the nonfishing trip option (Choice $\mathrm{C}$ ) and cost (COST). The SC model specification additionally contains a dummy variable for whether the fishing trip is taken with a private boat (PRIV) and the trip length $(D A Y)$. The first lines of Table 3 contain descriptions of these nonregulatory variables.

\section{Regulatory Variables}

Three categories of utility function attributes are needed to describe anglers' preferences for both past and present regulations, as well as potential regulations that have not been implemented, for the salmon and $\mathrm{Pa}$ cific halibut fisheries. The first two are uniform regulations (a bag limit or size limit applying to the entire day's harvest, which were used historically) and differentiated regulatory variables, which vary for individual fish in the bag limit and have been introduced relatively recently.

To date, regulators have only used uniform regulations for the Alaska salmon fisheries, and there do not appear to be any significant reasons for changing this strategy. In the Pacific halibut fishery, however, managers have been introducing two other categories of regulations: differentiated regulations and compound regulations that either use combinations of size and bag limits, or apply differently for individual fish in the daily harvest, or both.

The salmon fisheries regulations of interest here use just uniform bag limits, which determine the maximum number of fish that can be caught in a day fishing without size limits. ${ }^{8}$ As a result, the part of the utility function pertaining to Chinook (king) salmon

\footnotetext{
${ }^{8}$ There are longstanding size-differentiated regulations for Chinook salmon in both Southeast and Southcentral Alaska, but these are not the
} subject of this study. 
includes dummy variables for bag limits of one (KLIM1), two (KLIM2), or three (KLIM3) fish, which cover the range of bag limits actually observed (Table 3). For coho (silver) salmon, dummy variables for bag limits of three (SLIM1), four (SLIM2), and six (SLIM3) fish are used, corresponding to the higher harvest levels permitted in that fishery.

Fishing regulations in the Pacific halibut fishery are more complex. Bag limits have been the primary harvest control tool used in this fishery, but beginning in 2007, compound halibut management regulations were introduced for the charter (guided) fishing sector in Southeast Alaska (International Pacific Halibut Commission [IPHC] regulatory area $2 \mathrm{C}$ ), in part due to this sector's rapid growth and concomitant increase in harvests. During 2007-08, halibut harvest was managed with a compound regulation consisting of a 2 -fish bag limit, with one fish of any size and the other subject to a maximum size limit. In 2009 and 2010, halibut harvest was limited to one fish of any size on charter vessels. In 2011, a compound regulation with a bag limit of one halibut no larger than 37 inches (about $23 \mathrm{lb}^{9}$ ) was introduced. A further permutation of

\footnotetext{
${ }^{9}$ Standard Pacific halibut length-weight tables available from the IPHC were used to convert minimum size length restrictions into pounds (whole fish), which is the metric most commonly used by Alaska anglers when discussing fish size and the metric used to represent size in the survey discussed in this study. The weight of a fish without its head and entrails is assumed to be $75 \%$ of the whole fish weight.
}

the compound limit structure was introduced in 2012, with a "reverse slot" regulation that consists of both a maximum size limit and a minimum size limit, with the latter larger than the former. ${ }^{10}$

In 2012-13, the reverse slot regulation in effect was one halibut less than 45 inches (about $43 \mathrm{lb}$ ) or greater than 68 inches (about $163 \mathrm{lb}$ ). In 2014, this was modified slightly so that the maximum size limit was 44 inches (about $40 \mathrm{lb}$ ), with the bag limit and minimum size limit parts of the regulation remaining the same. However, in 2015, the maximum size limit was reduced to 43 inches while the minimum size limit was increased to 80 inches (about $272 \mathrm{lb}$ ), which restricted charter anglers in Southeast Alaska to smaller fish or very large fish. Additionally, 2014 marked the first time harvest by charter boat anglers in Southcentral Alaska (IPHC regulatory area 3A) was made subject to a compound regulation, with one of the fish in the two fish bag limit being restricted to 29 inches (about $10 \mathrm{lb}$ ) or less. The same regulations were used in Southcentral Alaska during 2015. Given these recent trends in charter halibut regulations, the use of compound regulations, particularly reverse slot regulations, appears likely to continue. ${ }^{11}$

\footnotetext{
${ }^{10} \mathrm{As}$ noted in the introduction, the reverse slot allows the angler to retain either a small or a very large fish, with the goal of the restriction being to protect the breeding stock, which are intermediate in size.

${ }^{11}$ Note that under the Guided Angler Fish provision of the Catch Sharing Plan, which became effective in 2014, charter boat anglers may in
}

This brief discussion of recent Alaska Pacific halibut regulation makes clear that the interaction of bag limits and two size limits creates many possible regulatory outcomes for Pacific halibut, particularly for the charter fishing sector. The number of fish in a bag limit that are subject to size limit(s), the number that are not, and the levels of the size limits are all potentially important considerations for anglers. In addition, it is important to try to provide information on regulations that may be used in the future. Thus, the utility functions in this study embody considerably more halibut regulation attributes than salmon regulation attributes. ${ }^{12}$

The specific regulatory attributes for Pacific halibut are also listed in Table 3. The additional uniform regulatory variables defined are dummy variables for halibut bag limits of one (HLIM1), two (HLIM2), or three (HLIM3) fish, and an integer variable (HBL, taking values of $0,1,2$, or 3 ) representing the number of fish allowed in the bag limit. A final uniform regulation is a dummy variable (HMIN) indicating whether a minimum size limit is in effect; both this and HBL are used in defining compound regulations, which are described in Table 4.

Table 3 also presents several differentiated regulatory variables. They

some circumstances be able to harvest fish outside of these size limits. For details, see NOAA (2013).

${ }^{12}$ At present, we are not aware of any plans to significantly alter the suite of harvest regulations in the salmon fisheries. 
Table 5. - Southeast Alaska (SE) model estimation results $(N=335){ }^{1}$

\begin{tabular}{|c|c|c|c|c|}
\hline \multirow[b]{2}{*}{ Variable } & \multicolumn{2}{|c|}{ Mean parameter } & \multicolumn{2}{|c|}{ Standard deviation parameter } \\
\hline & Estimate & Asymptotic t-value & Estimate & Asymptotic t-value \\
\hline \multicolumn{5}{|c|}{ Nonregulatory attributes } \\
\hline ASC & -1.235 & -3.989 & 4.206 & 12.555 \\
\hline $\operatorname{cosT}^{2}$ & -0.013 & -6.380 & & \\
\hline \multicolumn{5}{|c|}{ Uniform regulatory attributes ${ }^{3}$} \\
\hline HLIM1 & 1.466 & 7.843 & -0.984 & -2.911 \\
\hline HLIM2 & 2.182 & 10.328 & -1.879 & -7.861 \\
\hline HLIM3 & 2.115 & 8.469 & 2.171 & 7.619 \\
\hline KLIM1 & 0.998 & 5.588 & -0.792 & -2.498 \\
\hline KLIM2 & 0.976 & 6.138 & 0.653 & 2.267 \\
\hline KLIM3 & 1.035 & 4.533 & -0.204 & -0.467 \\
\hline SLIM1 & 1.291 & 7.370 & 0.805 & 2.536 \\
\hline SLIM2 & 1.821 & 9.845 & 0.779 & 3.254 \\
\hline SLIM3 & 1.648 & 7.615 & -1.220 & -4.319 \\
\hline
\end{tabular}

${ }^{1}$ Note: Parameters in bold are statistically significant at the $5 \%$ level.

${ }^{2}$ Trip cost is estimated as a fixed parameter; all others parameters are random.

${ }^{3}$ All trips are unguided (private) boat trips.

include dummy variables indicating whether the first fish in the bag limit (HMAX1) or additional fish in the bag limit (HMAX2) have maximum size limits; and integer variables (HSIZE1 and HSIZE2) indicating what those limits are. In addition, dummy variables define whether the first fish (HNOMAX1) or other fish (HNOMAX2) in the bag limit can be any size or are restricted by a size limit.

Table 4 describes compound regulations that include the reverse slot option and other options that treat individual fish in the bag limit differently. The first set of regulations applies to trips where there is not a reverse slot restriction, but there is a bag limit and a maximum size limit on one or more fish. (These regulations pertain to cases where only a maximum size limit, not a maximum and a minimum, is in effect.) Three dummy variables (HBL1FSH, HBL2FSH, and HBL3FSH) define whether the first, second, or third fish in the bag limit (when applicable) are subject to a maximum size limit. The parameters estimated when these variables are in the model correspondingly measure the marginal utility of the $i$ th fish $(i=$ $1,2,3)$ when it is subject to a maximum size limit.

In addition, since the marginal utility of a size-limited fish may vary depending on the maximum size limit itself, there are three additional dummy variables for the different fish in the bag limit that indicate whether a maximum size limit is applied to that fish. HBL1MAX1 equals one when there is a maximum size limit on the first (only) fish in a 1-fish bag limit, and zero otherwise; similarly, HBL3MAX1 and HBL3MAX2 equal one when there is a maximum size limit on the first and second fish in a multi-fish bag limit, respectively.

Table 4 also contains definitions and descriptions of a set of conditional dummy variables that exactly parallel those just described, but apply to fishing trips where there is a reverse slot option. Thus, HML1FSH, HML2FSH, and HML3FSH are dummy variables for the first, second, and third fish, respectively, with maximum size limits when at least one of them is a part of a reverse slot regulation. HML1MAX1, HML3MAX1, and HML3MAX2 are dummy variables that indicate which fish in the bag limit, if any, has a maximum size limit level imposed on it when there is a one-bag limit (HML1MAX1) or a multi-fish bag limit (HML3MAX1 and HML3MAX2).

\section{Estimation Results}

Panel-ordered mixed logit models were estimated using maximum simulated likelihood estimation (Train, 2003; Lew and Larson, 2012) for each sample (SE and SC samples), and the resulting parameter estimates are presented in Table 5 (for Southeast Alaska) and Table 6 (Southcentral Alaska). The estimated models allowed for all noncost parameters to be normally distributed over the population. ${ }^{13} \mathrm{~A}$

\footnotetext{
${ }^{13}$ Several alternative model specifications were tried that treated the regulatory variables differently, but they were not qualitatively different from the model presented here. They are available upon request from the authors.
}

Table 6. - Southcentral Alaska (SC) model estimation results $(N=430) .{ }^{1}$

\begin{tabular}{|c|c|c|c|c|}
\hline \multirow[b]{2}{*}{ Variable } & \multicolumn{2}{|c|}{ Mean parameter } & \multicolumn{2}{|c|}{ Standard deviation parameter } \\
\hline & Estimate & Asymptotic t-value & Estimate & Asymptotic t-value \\
\hline \multicolumn{5}{|c|}{ Nonregulatory attributes } \\
\hline ASC & 2.267 & 2.794 & 4.225 & 13.309 \\
\hline PRIV & 4.041 & 5.919 & 2.547 & 9.0870 \\
\hline DAY & -0.126 & -0.165 & 0.799 & 7.213 \\
\hline DAY squared & -0.155 & -0.821 & 0.152 & 4.203 \\
\hline $\operatorname{cost}^{2}$ & -0.002 & -3.618 & & \\
\hline \multicolumn{5}{|c|}{ Uniform regulatory attributes } \\
\hline PB_HLIM1 ${ }^{3}$ & 1.730 & 4.107 & -2.878 & -5.998 \\
\hline PB_HLIM2 & 3.124 & 9.776 & -0.687 & -2.032 \\
\hline PB_HLIM3 & 3.044 & 4.649 & -3.556 & -4.777 \\
\hline PB_KLIM1 & 0.598 & 1.446 & -2.386 & -4.951 \\
\hline PB_KLIM2 & 0.400 & 1.122 & -0.415 & -1.021 \\
\hline PB_KLIM3 & 0.755 & 1.894 & 1.391 & 2.665 \\
\hline PB_SLIM1 & 2.122 & 5.254 & -1.153 & -1.681 \\
\hline PB_SLIM2 & 1.041 & 2.847 & 1.537 & 4.103 \\
\hline PB_SLIM3 & 1.290 & 3.266 & 0.951 & 1.710 \\
\hline CH_HLIM1 1 & -0.544 & -0.754 & 0.4879 & 0.929 \\
\hline CH_HLIM2 & 0.722 & 1.0168 & 0.885 & 2.179 \\
\hline CH_HLIM3 & 1.493 & 1.466 & 0.045 & 0.061 \\
\hline CH_KLIM1 & 0.664 & 1.379 & -2.411 & -4.618 \\
\hline CH_KLIM2 & 1.586 & 3.827 & -0.367 & -0.844 \\
\hline CH_KLIM3 & 1.027 & 2.028 & -0.988 & -1.779 \\
\hline CH_SLIM1 & 1.708 & 3.144 & -1.508 & -3.404 \\
\hline CH_SLIM2 & 0.976 & 2.256 & -0.935 & -2.250 \\
\hline CH_SLIM3 & 0.598 & 1.446 & -2.386 & -4.951 \\
\hline
\end{tabular}

${ }^{1}$ Note: Parameters in bold are statistically significant at the $5 \%$ level. Parameters in italics are statistically significant at the $10 \%$ level.

${ }^{2}$ Trip cost (number of days times per-day cost) is estimated as a fixed parameter; all others parameters are random.

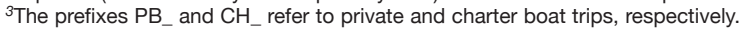


Table 6 (continued). -Southcentral Alaska (SC) model estimation results. ${ }^{1}$

\begin{tabular}{|c|c|c|c|c|}
\hline \multirow[b]{2}{*}{ Variable } & \multicolumn{2}{|c|}{ Mean parameter } & \multicolumn{2}{|c|}{ Standard deviation parameter } \\
\hline & Estimate & Asymptotic t-value & Estimate & Asymptotic t-value \\
\hline \multicolumn{5}{|c|}{ Differentiated regulatory attributes } \\
\hline HALSIZE1 & 0.029 & 0.820 & -0.086 & -6.801 \\
\hline HALSIZE2 & -0.049 & -2.228 & 0.020 & 1.727 \\
\hline HNOMAX1 & -0.470 & -0.510 & -2.136 & -4.813 \\
\hline HNOMAX2 & -0.619 & -0.618 & -0.811 & -2.017 \\
\hline \multicolumn{5}{|c|}{ Compound regulatory attributes } \\
\hline HBL1FSH & 1.381 & 1.442 & 0.355 & 0.806 \\
\hline HBL1MAX1 & -0.736 & -0.575 & -2.883 & -3.533 \\
\hline HBL2FSH & 0.663 & 0.774 & -0.703 & -1.425 \\
\hline HBL3FSH & -0.343 & -0.350 & -0.504 & -0.563 \\
\hline HBL3MAX1 & -0.073 & -0.080 & -0.585 & -1.143 \\
\hline HBL3MAX2 & -0.378 & -0.361 & -1.020 & -2.381 \\
\hline HML1FSH & 3.888 & 4.121 & 1.813 & 4.910 \\
\hline HML1MAX1 & -3.0135 & -2.821 & 1.060 & 1.365 \\
\hline HML2FSH & -0.388 & -0.590 & 0.588 & 1.436 \\
\hline HML3FSH & 0.766 & 0.770 & 0.870 & 1.003 \\
\hline HML3MAX1 & 0.796 & 0.751 & 0.768 & 1.813 \\
\hline HML3MAX2 & -3.540 & -3.207 & 1.178 & 2.679 \\
\hline Mean log-likelihood & -5.150 & & & \\
\hline AIC (corrected) & 4616.565 & & & \\
\hline $\mathrm{BIC}$ & 4895.352 & & & \\
\hline
\end{tabular}

${ }^{1}$ Note: Parameters in bold are statistically significant at the $5 \%$ level. Parameters in italics are statistically significant at the $10 \%$ level. All differentiated and compound regulatory parameters are for charter boat fishing trips only. Standard deviation parameters can be positive or negative, but only the absolute value has meaning in the estimation program and in interpretation of results.

comparison of the mixed logit model results with those from conditional logit models for each specification showed significant improvement in statistical fit by introducing preference heterogeneity by way of random parameters for both the SE and SC models. In fact, as Table 5 presents, 9 of the 10 random parameters in the SE model had statistically significant standard deviation parameters, indicating respondents across the sample varied in terms of how their utility was affected by most of the noncost variables.

The ASC mean parameter was negative and statistically significant, indicating that on average the nonsaltwater boat fishing trip option (Choice C) was not preferred over the saltwater boat fishing trip options, which are assumed for the SE sample to be private boat fishing trips. However, the large and significant standard deviation parameter associated with the ASC suggests there was considerable variation in preferences toward the nonsaltwater boat fishing option across the sample with some preferring it to the fishing options and others preferring the fishing options.

The other mean parameters were generally statistically significant with the expected signs: the cost parameter was negative and highly significant, while all of the regulatory attributes, which are uniform bag limits of different sizes for the three species (Pacific halibut and Chinook and coho salmon) were positive and statistically significant, suggesting there is utility to being allowed to fish (i.e., having a nonzero bag limit). The bag limit mean parameter estimates along with their standard errors (implied by the asymptotic t-statistics) indicate that for halibut and coho salmon, the second fish in the bag limit is valued more highly than the first fish, with no difference in valuation of a 2-fish limit vs. a 3-fish limit for halibut and between a 4-fish and 6-fish limit for coho salmon. Thus, for the average SE resident angler (i.e., evaluating at the mean parameter estimates), there is increasing marginal utility for the first and second fish bag limit but zero marginal utility from relaxing the bag limit to the third level (three fish for halibut and six fish for coho). For Chinook salmon, there is no statistical difference between any of the bag limit mean parameter estimates, implying positive marginal utility of the first fish and zero marginal utility of the second and third fish.

Table 6 presents the results for the SC sample, which contains resident angler respondents who were presented $\mathrm{CE}$ questions with both private boat and charter boat fishing trip options. The model results indicate a general preference for the status quo (nonsaltwater boat fishing) option; the mean estimate is significantly positive, and its magnitude relative to the standard deviation estimate suggests that it is positive for the majority of $\mathrm{SC}$ anglers. Additionally, they indicate a strong preference for private boat trips relative to charter boat trips, all else being equal: the mean parameter estimate (4.04) relative to the standard deviation estimate (2.55) implies that a large majority of the population of anglers in this region prefers private boat trips. Of the other nonregulatory attributes, trip length (represented by the DAY and DAY squared variables) had a statistically insignificant mean effect, but the significant standard deviations on these variables indicate a considerable dispersion of preferences for trip length in the population. The cost parameter, as expected, was negative and highly significant.

Of the regulatory attributes, the parameter estimates on the uniform bag limits are the most straightforward to interpret in isolation. For private boat trips, bag limits had statistically significant positive mean effects for halibut and coho salmon, but statistically insignificant effects for Chinook salmon, except for the 3-fish bag limit, which is significant and positive (at the 10\% level). For halibut, the means of 2- and 3-fish bag limits were both substantially higher than for a single fish bag limit, with no appreciable difference between them. For coho salmon, this was reversed: a 3-fish bag limit had a substantially higher marginal utility than did 4- and 6-fish bag limits, with no appreciable difference between the latter two.

For charter trips, Chinook salmon bag limits (with 2- and 3-fish limits) and coho salmon bag limits (with 3- and 4-fish limits) had statistically significant positive mean effects; the remaining mean effects were insignificant. The significant standard deviation parameters for 2-fish halibut limits, 1-fish Chinook salmon limits, and all of the coho salmon bag limits 


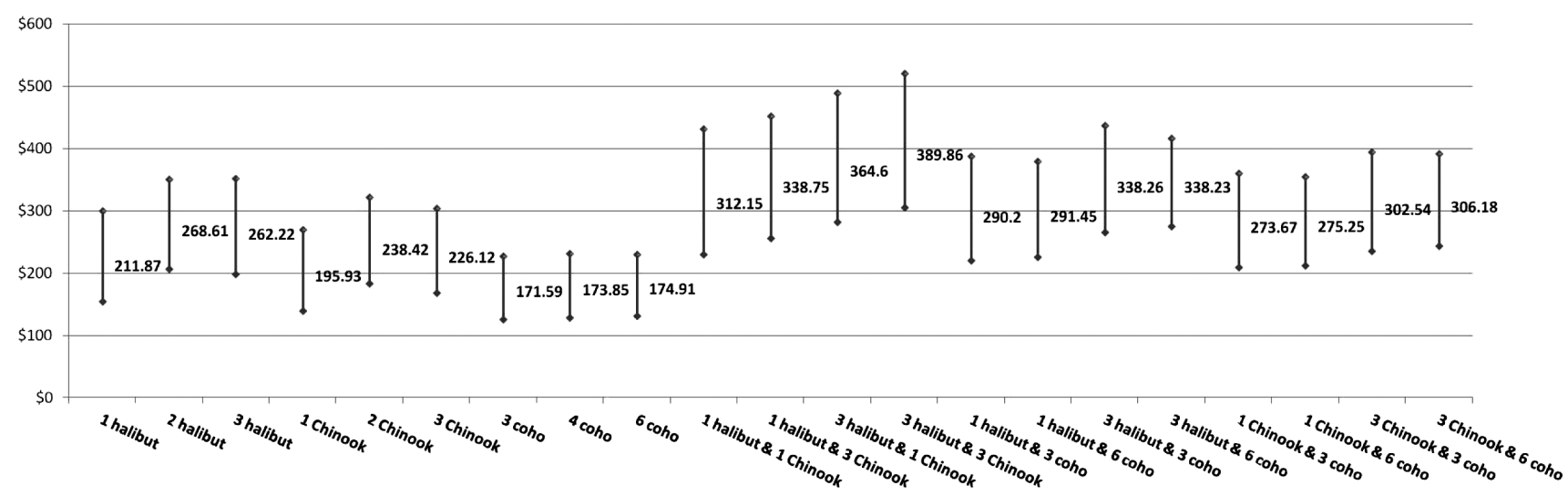

Figure 4.-Total economic values and associated 95\% confidence bounds of Southeast Alaska resident anglers for private-boat saltwater trips with different bag limits.

indicate statistically significant dispersion of mean effects.

Each differentiated regulatory attribute had either a significant mean effect or a significant standard deviation. The significant and negative mean and insignificant standard deviation for HALSIZE2, which indicates maximum size limits on all fish in the bag limit beyond the first one, shows a uniform dislike for the regulation. The insignificant mean and significant standard deviation on HALSIZE1 (maximum size limit on the first fish) indicate that some people like, and some dislike, the regulation (independent of HALSIZE2). The same is true for HNOMAX1 and HNOMAX2, which indicate the presence or absence of size limits (whether maximum or minimum) on the first and additional fish, respectively, in the bag limit: some in the population like and some dislike size regulations.

The compound regulations place maximum size limits on one or more fish in the bag limit, with or without minimum size limits. The first set of compound regulation variables (HBL1FSH, HBL2FSH, HBL3FSH, HBL1MAX1, HBL3MAX1, HBL3MAX2), which define maximum size limits only, are generally not statistically significant; only the standard deviation parameters on HBL1MAX1 and HBL3MAX2 are statistically significant, which only in- dicate utility variation across anglers for maximum size limits. The second set of compound regulation variables (HML1FSH, HML2FSH, HML3FSH, HML1MAX1, HML3MAX1, HML3MAX2) define the reverse slot or combination maximum and minimum size limits, which relative to the first set of variables add the option to catch and retain a very large fish when there is a (maximum) size limit in effect.

The reverse slot option when there is a 1-halibut bag limit (HML1FSH) has a statistically significant positive effect on angler utility. In the presence of the reverse slot option, angler utility decreases with increases in the maximum size limit (lower size limit in the reverse slot restriction) when a 1-fish bag limit is in effect (HML1MAX1) and for all but the first fish when a multiple fish bag limit is in effect (HML3MAX2).

The interactions of these variables cover four of the six cases for regulating individual fish in bag limit limits of up to 3 fish: the only cases not covered are the first fish in a 2- or 3-fish bag limit. These latter two cases are situations where only HML2FSH is in effect, for which there is not a significant effect on utility. For the other cases discussed above, both HML1FSH and HML1MAX1 are in effect, and there is a small (net) positive effect on utility. To summarize these implications, for trips with a reverse slot option to catch a very large fish and a single fish bag limit, there is a positive effect on utility. When the reverse slot option is used on one or more fish with a multi-fish bag limit, the effect on utility is negative, all else being equal.

\section{Economic Values for Fishing}

Two types of economic values are calculated using the SE and SC model estimation results: marginal economic values of an attribute associated with a one unit change and the total economic value of, or willingness to pay (WTP) for, a fishing trip with a specific set of attribute levels. The former are important for understanding the incremental effect that trip characteristics, such as the type of boat used and regulations, have on the value of charter fishing trips with all else held constant. In contrast, total economic values of fishing trips represent the WTP for a fishing trip given a specific set of regulations on target species, as they may vary by the type of boat used and area fished.

Figure 4 displays estimates of total value for Southeast Alaska trips with different types of uniform bag limits and $95 \%$ confidence bounds for the estimated values (calculated using the Krinsky and Robb, 1986, simulation-based method). These are values associated with 1-day trips on private boats, and all have bag limits of 


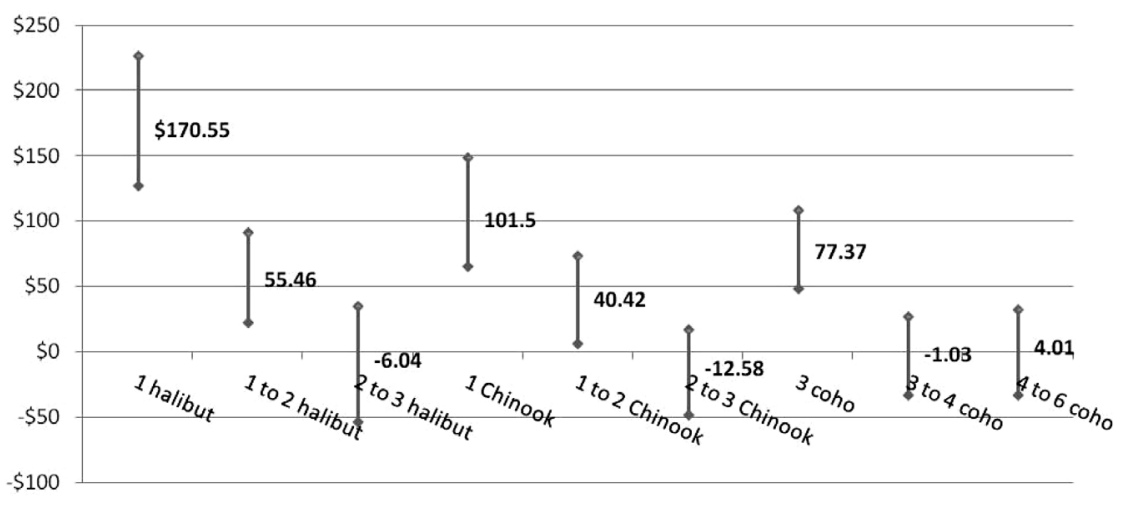

Figure 5.-Marginal values and associated 95\% confidence intervals of bag limit changes in Southeast Alaska saltwater fisheries.

different levels. Different values are presented for fishing trips that target different species-some trip values are for single species trips where one species is caught and others are for trips on which more than one species is caught. For single-species bag limit trip values, the mean ranged from about $\$ 172$ to $\$ 269$, and all of the lower 5\% levels of the confidence intervals are above zero, indicating that total value is strictly positive. Halibutonly and Chinook-only trips with 2or 3-fish bag limits have higher mean total values than those with 1-fish bag limits, while for coho salmon trips there is no appreciable difference in mean total value regardless of the bag limit (i.e., the confidence intervals are almost identical).

Values associated with trips on which two species are caught are presented for each of the three 2-species combinations ranging from the lowest to highest level of bag limit for each species. Halibut-Chinook trips had mean total values ranging from $\$ 312$ to $\$ 390$, while halibut-coho mean trip values ranged from $\$ 290$ to $\$ 338$ and Chinook-coho trip values ranged from $\$ 273$ to $\$ 306$.

Marginal values of bag limits and associated confidence bounds for each species from the SE model are presented in Figure 5. For each species, the first fish in the bag limit was the most valuable (or, the first three fish for coho salmon), with mean mar- ginal values of 1-fish bag limits being \$171 for Pacific halibut, \$102 for Chinook salmon, and $\$ 77$ for coho salmon trips. For both Pacific halibut and Chinook salmon trips, there was a decreasing positive mean marginal utility of the second fish in the bag limit (\$55 and \$40, respectively), while for coho salmon the mean marginal values of both the increase to 4 fish from 3 fish and to 6 fish from 4 fish in the bag limit were not different from zero statistically.

Total economic values for Southcentral Alaska private boat trips (and the associated confidence bounds) are presented in Figure 6. Private boat trips in Southcentral Alaska were valued more highly than those in Southeast Alaska, with mean total values for halibut-only trips ranging from $\$ 1,415$ to $\$ 2,083$ depending on the bag limit, from $\$ 831$ to $\$ 973$ for Chinook salmon-only trips, and from $\$ 1,119$ to $\$ 1577$ for coho salmononly trips. As in Southeast Alaska, the lower bounds on the confidence intervals were positive in every case, indicating clearly that the total values are statistically significant and positive. Unlike for the Southeast Alaska trip values, though, there was generally not a clear trend in how total values change with increases in the bag limit; only for an increase from 1 to 2 fish in the Pacific halibut bag limit was there evidence of a (statistically significant) positive change in mean total value (indicated by non-overlapping confidence intervals).

Multiple-species private boat trips in Southcentral Alaska also had mean total values that were considerably higher than those for Southeast Alaska. Not surprisingly, total values for the halibut-coho combination were the highest since these are the highest valued in single-species trips. Adding either halibut or coho to a Chinook salmon trip increases mean total value substantially, while conversely, adding Chinook to either a halibut or coho trip increases mean total value only modestly, by less than one-half of the single-species Chinook mean value.

Strikingly, however, total economic values for charter boat trips in Southcentral Alaska were effectively zero in every case and are therefore not presented. The basic result is that Southcentral Alaska resident anglers on average do not have positive total values for saltwater charter boat fishing trips regardless of the species targeted or regulations. In other words, the mean values for Southcentral Alaska charter boat trips are not statistically different from zero (and in the case of some trips under certain regulations the total trip value was statistically negative). This means the demand for charter boat fishing trips is zero for the average Southcentral Alaska resident angler. This result is not particularly surprising within our model in light of the fact that both the alternativespecific constant (indicating preference for the nonfishing option) and the parameter on the private boat dummy variable were highly significant and positive with large magnitudes. Additionally, the statistical noise around the parameter estimates associated with the charter-specific variables, most of which were not statistically significant, is also likely a major reason for this result. Additional discussion of this is in the next section.

Figure 7 presents the marginal values of trip attributes (and associated confidence intervals) for all Southcentral Alaska saltwater fisheries private boat trips. Reinforcing the point made earlier about private boat trips 


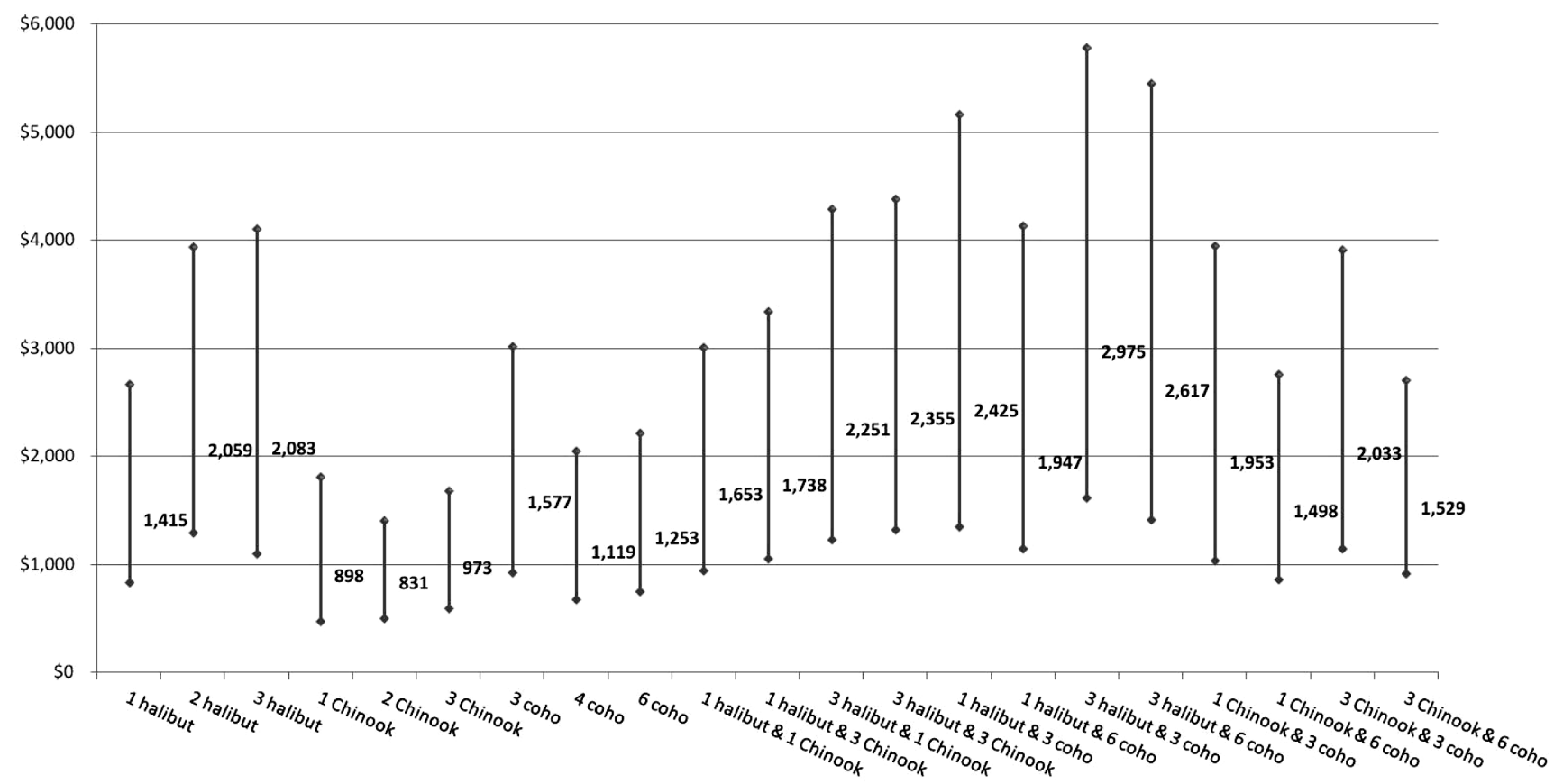

Figure 6.-Total economic values of Southcentral Alaska resident anglers for private-boat saltwater trips with different bag limits.

increasing angler utility, the marginal value of a trip being taken on a private boat, all else equal, is statistically greater than zero with a mean marginal value of about $\$ 1,811$. For private boat Pacific halibut trips, the mean marginal value of both the increase from 0 to 1 fish and from 1 to 2 fish is positive and significant, while the marginal value of an increase from 2 to 3 fish is not significantly different from zero. For both Chinook and coho salmon trips on private boats, the marginal values of all levels of bag limit increase are not significantly different from zero.

For charter boat Southcentral Alaska trips, most of the marginal values of bag limit increases are not different from zero (Fig. 8). However, for both Pacific halibut and Chinook salmon the marginal value of an increase in bag limit from 1 to 2 fish is significantly positive, as is the increase from 0 to 3 fish in the coho salmon bag limit. However, due to the magnitudes of angler preference for the non-saltwater fishing option, these significant and positive marginal values are not suffi- cient to shift the total value of saltwater charter fishing trips to be positive.

\section{Discussion}

The estimation results and estimated economic values make several points about the Alaska resident saltwater salmon and Pacific halibut fisheries. First, the economic value of the private boat fishery in Southeast Alaska (the predominant way of fishing by residents) is positive and significant, with single-species 1-day trips generating mean total economic values in the range of \$172-269, depending on species harvested and the bag limit. Second, the Southcentral Alaska private boat fishery also generates positive and significant total values, and these are considerably larger than in Southeast Alaska: for single-species trips, the mean total value of a 1-day trip ranged from about $\$ 831$ to $\$ 2,083$. Third, in both these fisheries, 2-species trips generally are valued more highly than single-species trips, though there is declining marginal value to adding a second species harvest to the trip. Fourth, there is not much evidence that increases in bag limits beyond the first fish for single-species trips increases the total value of a trip. The increase in the Pacific halibut bag limit in Southcentral Alaska from 1 to 2 fish may be the possible exception.

The only charter fishery engaged in by Alaska residents in substantial numbers is the one in Southcentral Alaska. Here, the modeling and economic value estimates indicate strongly that the average total economic value of trips with characteristics similar to those available to anglers in recent years (or any others we tried) is not statistically positive. The estimation results indicate very clearly two facts that explain why. First is a strong preference toward the nonfishing option when compared with charter boat trips, which is indicated by the highly significant, positive, and large coefficient on the alternative-specific constant in the Southcentral Alaska fishery (ASC in Table 6). For the private boat fishery, this is fully offset by the large positive and significant coefficient on the private boat dummy variable (PRIV) in this model. 


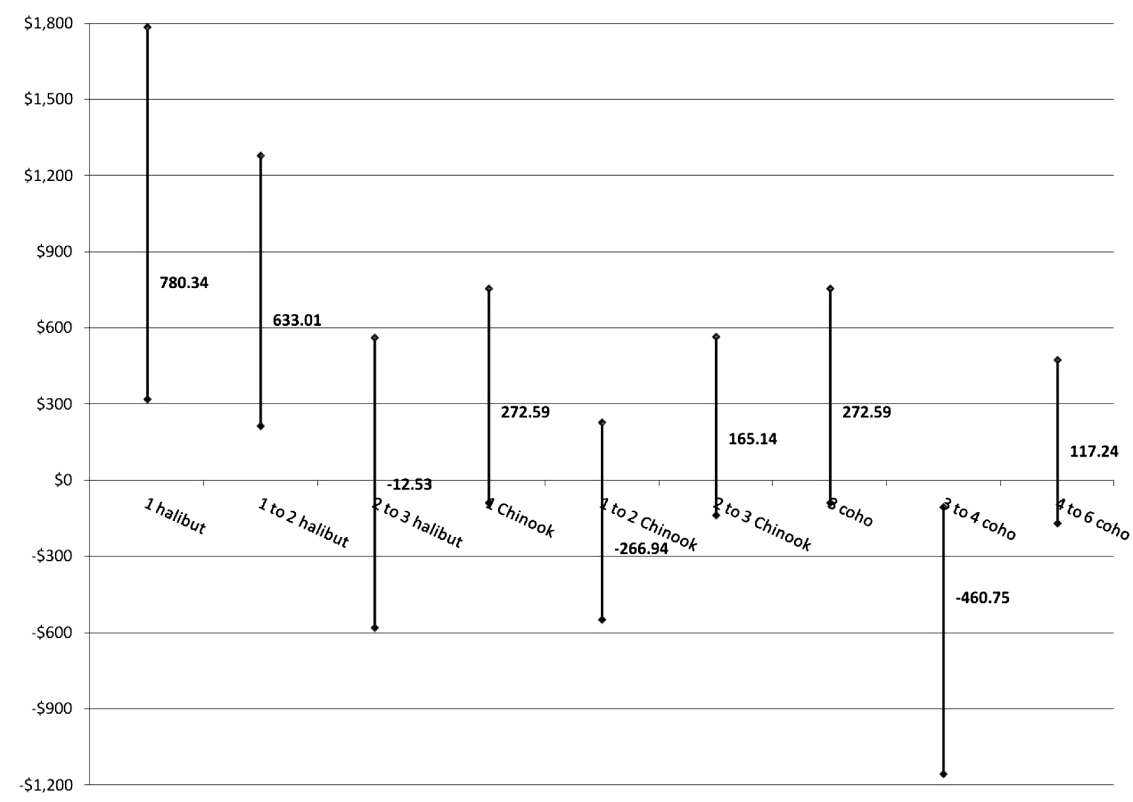

Figure 7.-Marginal values and associated $95 \%$ confidence intervals of bag limit changes for private boat saltwater fishing trips by Southcentral Alaska residents.

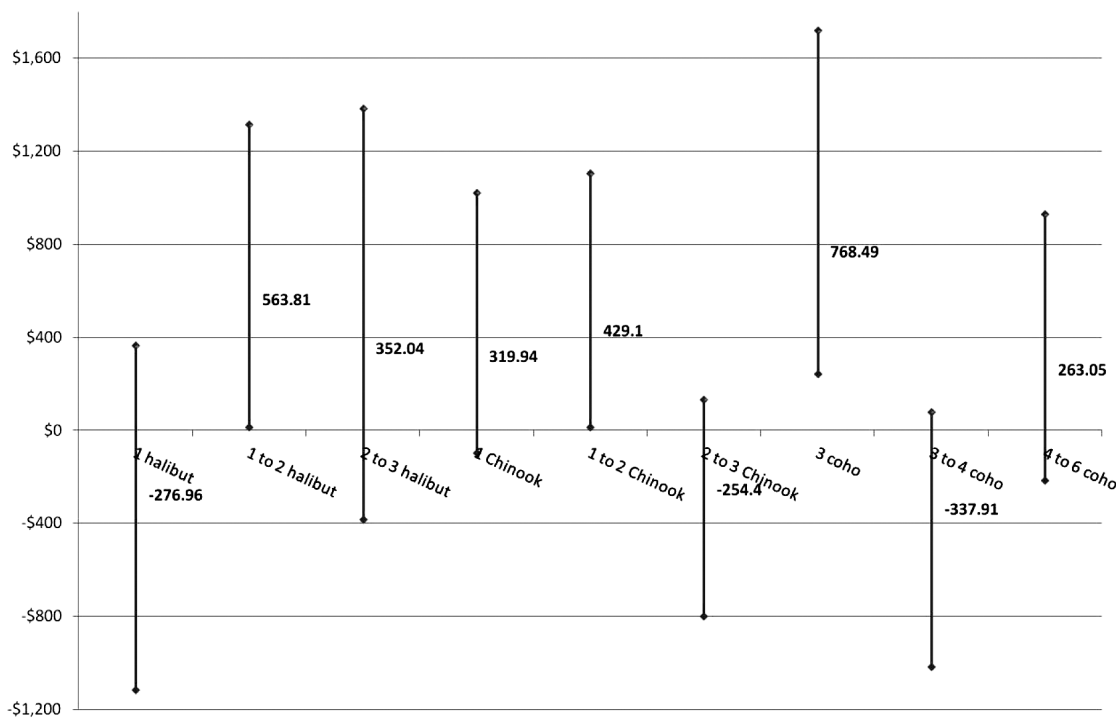

Figure 8.-Marginal values and associated $95 \%$ confidence intervals of bag limit changes for charter boat saltwater fishing trips by Southcentral Alaska residents.

This basic conclusion regarding Southcentral Alaska resident anglers' preferences is not changed by including the specific regulations that have been used recently. The reason is that there is virtually no net impact on utility from including most of the differ- size limits with the reverse slot option do have significant mean effects, but their combined effect is near zero for most of the regulatory scenarios possible.

This does not mean that charter boat fishing trips in Southcentral Alaska have no overall total economic value, since the discussion here is just of Alaska residents' preferences. Lew and Larson (2015) found that for nonresidents of Alaska, charter trips with more than a 1-fish bag limit, and those which did not have very small maximum size limits (23 lb in their analysis), had total values of 1-day trips that exceeded $\$ 1,150$ in every case considered, with several regulatory scenarios generating total values exceeding $\$ 2,000$. Trips with a 1-fish bag limit and a $23 \mathrm{lb}$ maximum size limit generated total economic values of about $\$ 330$.

However, each of the Southcentral Alaska charter boat fishing trips with differentiated or compound halibut regulations generated in this study had mean total values to Alaska residents that were not statistically different from zero, while the same trip types generated significantly positive total values to nonresidents of Alaska in the Lew and Larson (2015) study. This suggests that charter boat halibut trips have large total values for the fishery as a whole, but that most of it accrues to nonresidents.

Importantly, at the time of the survey, Southcentral Alaska charter boat trips were not subject to any of the size restrictions asked about in the $\mathrm{CE}$ questions. At that time, charter boat anglers in Area 3A were allowed to catch and keep two fish of any size. Thus, in this study SC respondents were asked to choose between fishing trip alternatives that were much stricter in terms of the regulations imposed on charter halibut fishing than they were accustomed to. This likely explains the strong preference for private boat trip alternatives and the nonboat saltwater fishing trip option, which likely greatly contributed to the finding of there being effectively zero demand for saltwater charter fishing trips. 
Since this study used data from the same survey effort and a modeling approach similar to Lew and Larson (2015), it is worth briefly mentioning the caveats they discuss that apply here. First, the scenarios we analyze cannot be taken literally as assessments of the economic value of current regulations, since there are some differences between what was anticipated when the study was designed and what regulations were actually implemented. Probably the biggest difference is in the minimum size thresholds for the reverse slot option, which are $130 \mathrm{lb}$ in our scenarios but larger in the actual regulations. This may increase the angler's perception of their chance of being able to keep a large fish, which in turn may increase their valuation of the reverse slot option. This seems unlikely to affect any conclusions in our analysis, since economic values in the halibut charter fishery were statistically zero.

Second, the experimental design was complex to attempt to best reflect the many facets of current halibut regulation. This large design contributed to the wide confidence intervals seen for many regulatory scenarios for halibut. (We have also estimated simpler specifications which aggregate many of the detailed regulatory attributes of this analysis, but the basic conclusions about the effects of regulation and economic values do not change qualitatively. ${ }^{14}$ ) This was not an issue for the salmon scenarios since they involved bag limits only and therefore required a relatively simple experimental design.

Third, the estimated total economic values are WTP values, not net economic values. Thus, the charter prices, which in recent years have ranged from about $\$ 300$ for a single day trip to about $\$ 1,500$ or more for a multiday trip, and travel costs (e.g., fuel) from the angler's home to the dock need to be accounted for. These costs must be subtracted from the WTP estimates presented in this paper to gen-

\footnotetext{
${ }^{14}$ These results are available on request from the authors.
}

erate net economic trip values. Fourth, the significance of the standard deviation terms suggests that heterogeneity of preferences across anglers is important, with considerable variation of total values of regulatory scenarios across the sample.

In addition to these caveats that are shared with the nonresident angler analysis in Lew and Larson (2015), we note several additional ones that are important limitations specific to our analysis of Alaska resident anglers. First, compared to the nonresident sample in Lew and Larson (2015) (of 825 respondents), the SC sample had roughly half as many respondents (430 resident anglers). However, the same fairly complex utility specification was applied in both studies. In the present case there were far fewer statistically significant parameters associated with the charter-specific halibut harvest regulations. It is possible this may be a product of the smaller sample being used in a complex model specification and there not being sufficient sample to isolate the effects of the regulatory attributes. ${ }^{15}$ Thus, given the complexity of contemporary regulations related to charter fishing in Alaska, future analyses may need to utilize much larger samples.

Second, we note that our Alaska resident samples are not limited to saltwater anglers. Among survey respondents in the SC sample, for example, half had fished in saltwater during the 2011 fishing season, and $21 \%$ had fished by charter boat (the remainder of the saltwater anglers had only fished by private boat or from shore). Our results, however, are based on analyzing $\mathrm{CE}$ responses from any Alaska resident angler who was licensed to fish in Alaska during 2011, regardless of their experience saltwater fishing.

\footnotetext{
${ }^{15}$ Technically, to isolate the marginal effects of variables in the RUM model, the attribute levels need to vary considerably across the alternatives seen by respondents, and there needs to be at least some people who choose alternatives that cover the range of attribute levels for the model to fit well. In this application, the smaller sample size $(N=435)$ may not have been sufficient for this purpose.
}

Although it is likely that preferences for saltwater fishing trips will differ between those who primarily fish in saltwater compared to those who primarily fish in freshwater, we do not distinguish or investigate these differences here since our principal goal was to generate estimates of saltwater fishing opportunities for all anglers, both those who have saltwater fished and those that would potentially do so. However, we acknowledge that future research can and should be done to investigate the differences in values and preferences between these angler types.

\section{Conclusions}

This article has presented results on the value of saltwater charter boat fishing trips to Alaska residents using data from a 2012 survey of nonresident anglers in a stated preference choice experiment analysis. The econometric estimation approaches utilized here followed those used in Lew and Larson (2015). Moreover, the results of this study are intended to complement the economic value information from Lew and Larson (2015), which consisted of economic values for saltwater fishing of Alaska nonresidents. Together, the two studies provide a relatively complete picture of saltwater angler preferences in Alaska (circa 2012), and the economic values they generate.

As with the previous study, an important goal is to be responsive to the potential needs of fishery managers for information about economic values when considering modifications to existing regulations. Because the regulatory landscape has been changing rapidly for Pacific halibut, a focus was placed primarily on regulations for that fishery. This is needed since an annual evaluation of recreational harvest regulations is now a formal part of the regulatory process under the newly-implemented halibut catch sharing plan (NOAA, 2013). Since recent regulations for Pacific halibut have been applied specifically to the charter sector in Alaska and are stricter than those applied to unguided anglers, 
understanding the role of regulations on the charter sector is especially important.

A second goal of the article is to increase the available knowledge about economic values associated with recreational charter boat fishing for both salmon and Pacific halibut in recent years, since regulations, personal preferences for fishing, and broad economic conditions change, and with them the economic values of fishing can change. Providing economic value information for each of the principal types of fishery users can help fishery managers better understand the effects that changes in regulations have on different groups of people, which often differ.

Our results indicate that the private boat fisheries for both Pacific halibut and salmon have significantly positive total economic values to Alaska residents. These values ranged from about $\$ 172$ to $\$ 2,083$ for 1-day trips, depending on the species harvested and the bag limit and which region in Alaska the fishing trip occurred. In contrast, the charter boat fisheries for these species have total trip values that are generally not statistically positive and thus indicate there is no significant demand among residents for the types of restrictive charter boat fishing trips that have been prevalent in recent years. The reasons for this appear to be the strong preferences of Alaska residents for private boat fishing or other options over saltwater charter boat fishing.

As a result, the differentiated and compound regulations that characterize recent Pacific halibut regulations in the charter boat sector had no practical effect on economic values in 2012, since the total values of charter boat trips are effectively zero with or without them. Additional findings are that private boat trips where two species are harvested have higher total value to anglers than single species trips, but it is a proportionately smaller increase in value. These values ranged from about $\$ 274$ to almost $\$ 3,000$, again depending on the species harvested, the bag limits, and in which region the trip occurred. Also, increases in bag limits, all else equal, had little discernible effect on total values, except possibly the case of increasing the bag limit from one to two fish in the Pacific halibut fishery.

Knowledge of the economic values of fisheries to anglers can be informative and useful in policy discussions. However, they are of course but one of numerous considerations that fishery managers must take into account when decisions are made.

\section{Acknowledgments}

The authors thank the Alaska Department of Fish and Game, particularly Gretchen Jennings and Bill Romberg, for access to data that was helpful in this study. They also thank Ron Felthoven, Sabrina Lovell, and Brian Garber-Yonts of the National Marine Fisheries Service, NOAA, and two anonymous reviewers for useful comments. All remaining errors or omissions are the responsibility of the authors. Funding support from the NMFS Office of Science and Technology is gratefully acknowledged. This article and its findings do not necessarily reflect the views of the National Marine Fisheries Service, NOAA.

\section{Literature Cited}

Anderson, L. E., and S. T. Lee. 2013. Untangling the recreational value of wild and hatchery salmon. Mar. Res. Econ. 28:175-197. (doi: https://doi.org/10.5950/0738-1360-28.2.175).

Bateman, I. J., R. T. Carson, B. Day, M. Hanemann, N. Hanley, T. Hett, M. Jones-Lee, G. Loomes, S. Mourato, E. Ozdemiroglu, D. W. Pearce, R. Sugden, and J. Swanson. 2002. Economic valuation with stated preference techniques: a manual. Edward Elgar, Northampton, Mass., $458 \mathrm{p}$.

Beggs, S., S. Cardell, and J. Hausman. 1981. Assessing the potential demand for electric cars. J. Econometrics 16:1-19. (doi: https://doi. org/10.1016/0304-4076(81)90056-7).

Carter, D. W., and C. Liese. 2012. The economic value of catching and keeping or releasing saltwater sport fish in the Southeast USA. N. Am. J. Fish. Manage. 32:613-625. (doi: https://doi.org/10.1080/02755947.2012.6759 43).

Chapman, R. G., and R. Staelin. 1982. Exploiting rank ordered choice set data within the stochastic utility model. J. Market. Res. 19(3):288-301. (doi: https://doi. org/10.2307/3151563).

Criddle, K. R., M. Herrmann, S. T. Lee, and C. Hamel. 2003. Participation decisions, angler welfare, and the regional economic impact of sportfishing. Mar. Res. Econ. 18:291-312. (doi: https://doi.org/10.1086/ mre.18.4.42629404).

Dillman, D. A., J. D. Smyth, and L. M. Christian. 2014 Internet, mail, and mixed-mode surveys: the tailored design method. John Wiley and Sons, 4th ed., Hoboken, N.J., 509 p.

Huber, J., and K. Zwerina. 1996. The importance of utility balance in efficient choice designs. J. Market. Res. 33(3):307-317. (doi: https://doi.org/10.2307/3152127).

Kanninen, B. J. 2006. Valuing environmental amenities using stated choice studies: a common sense approach to theory and practice. Springer, Dordrecht, Netherl., $336 \mathrm{p}$.

Krinsky, I., and A. L. Robb. 1986. On approximating the statistical properties of elasticities. Rev. Econ. Stat. 68:715-719.

Lew, D. K., and D. M. Larson. 2012. Economic values for saltwater sport fishing in Alaska: a stated preference analysis. N. Am. J. Fish. Manage. 32(4):745-759.(doi: https://doi.org/ 10.1080/02755947.2012.681012)

and 2014. Is a fish in hand worth two in the sea? Evidence from a stated preference study. Fish. Res. 157:124-135. (doi: https://doi.org/10.1016/j. fishres.2014.04.005). and 2015. Stated preferences for size and bag limits of Alaska charter boat anglers. Mar. Pol. 61:66-76. (doi: https://doi.org/10.1016/j. marpol.2015.07.007).

J. Lee, and D. M. Larson. 2010 Saltwater sportfishing in Alaska: a summary and description of the Alaska saltwater sportfishing economic survey, 2007. U.S. Dep. Commer., NOAA Tech. Memo. NMFS-AFSC-214, 229 p.

Louviere, J. C., D. A. Hensher, and J. D. Swait. 2000. Stated choice methods: analysis and applications. Camb. Univ. Press, U.K., 402 p.

Mitchell, R. C., and R. T. Carson. 1989. Using surveys to value public goods: the contingent valuation method. Resour. Future, Wash., D.C., $463 \mathrm{p}$.

NOAA. 2013. Pacific halibut fisheries; catch sharing plan for guided sport and commercial fisheries in Alaska. Final rule. 78 Fed. Regist. 75843 (15 Mar. 2013), p. 75,843-75,895. (Available online at https://www.gpo.gov/ fdsys/pkg/FR-2013-12-12/pdf/2013-29598. pdf).

Train, K. E. 2003. Discrete choice methods with simulation. Camb. Univ. Press, U.K., 334 p.

Willis, G. B. 2005. Cognitive interviewing: a tool for improving questionnaire design. Sage Publ., Thousand Oaks, Calif., 333 p. 